Published in final edited form as:

Mol Aspects Med. 2020 October ; 75: 100895. doi:10.1016/j.mam.2020.100895.

\title{
Molecular Aspects of Medicine
}

\author{
Romana R. Gerner ${ }^{1,2}$, Sean-Paul Nuccio ${ }^{1}$, Manuela Raffatellu ${ }^{1,3,4}$ \\ ${ }^{1}$ Division of Host-Microbe Systems and Therapeutics, Department of Pediatrics, University of \\ California, San Diego, La Jolla, CA \\ ${ }^{2}$ Division of Internal Medicine I, Department of Medicine, Innsbruck Medical University, Innsbruck, \\ Austria \\ ${ }^{3}$ Center for Microbiome Innovation, University of California, San Diego, La Jolla, CA \\ ${ }^{4}$ Chiba University-UC San Diego Center for Mucosal Immunology, Allergy, and Vaccines (CU- \\ UCSD cMAV), La Jolla, CA
}

\begin{abstract}
Iron is an essential micronutrient for nearly all living organisms. In addition to facilitating redox reactions, iron is bound by metalloproteins that participate in a variety of biological processes. As the bioavailability of free iron in host environments is extremely low, iron lies at the center of a battle for nutrients between microbes and their host. Mucosal surfaces such as the respiratory and gastrointestinal tracts are constantly exposed to commensal and pathogenic microorganisms. Whereas a key strategy of mammalian antimicrobial defense is to deprive microbes of iron, pathogens and some commensals have evolved effective strategies to circumvent iron limitation. Here we provide an overview of mechanisms underpinning the tug-of-war for iron between microbes and their host, with a particular focus on mucosal surfaces.
\end{abstract}

\section{Introduction}

Iron $(\mathrm{Fe})$ is a vital micronutrient for nearly all forms of life, and is involved in critical physiological processes including oxygen transportation, energy metabolism, and DNA replication (Lieu et al., 2001). By existing primarily in two oxidation states, ferrous $\left(\mathrm{Fe}^{2+}\right)$ and ferric $\left(\mathrm{Fe}^{3+}\right)$ iron, this element has the flexibility to serve as a key cofactor in many enzymes as well as play a crucial role in facilitating a variety of redox reactions. Nevertheless, despite iron's essential roles in the beneficial chemistry of life, its redox potential can negatively impact biological molecules and cells; for example, the Fenton reaction involving $\mathrm{Fe}^{2+}$ and hydrogen peroxide yields reactive oxygen species (ROS) that can damage biomolecules including lipids, proteins, and DNA. Oxidative stress, in turn, is linked to aging, cardiovascular disorders, neurodegenerative diseases, and cancer (Liu et al., 2018). To minimize iron's reactivity and toxicity, the vast majority of iron in mammals is found in intracellular compartments, complexed with hemoproteins (e.g., hemoglobin,

Publisher's Disclaimer: This is a PDF file of an unedited manuscript that has been accepted for publication. As a service to our customers we are providing this early version of the manuscript. The manuscript will undergo copyediting, typesetting, and review of the resulting proof before it is published in its final form. Please note that during the production process errors may be discovered which could affect the content, and all legal disclaimers that apply to the journal pertain. 
myoglobin), or the iron-storage protein ferritin (Lieu et al., 2001). Thus, the bioavailability of free iron is low in the mammalian environment, even during homeostasis. Moreover, in a process known as nutritional immunity, extracellular and intracellular iron is further decreased during infection to prevent the outgrowth of pathogens (Hood and Skaar, 2012). Successful pathogens have therefore evolved strategies to compete for and obtain iron from the host in order to replicate and thrive despite limited nutrient availability.

Mucosal surfaces constitute a physical barrier between the external environment and the inner body. During homeostasis, many of these surfaces are colonized by an assortment of microbes that are collectively referred to as the commensal microbiota, and typically include non-pathogenic bacteria, fungi, archaea, and viruses (Lozupone et al., 2012). Among the body sites with a commensal microbiota, the gastrointestinal (GI) tract, and in particular the colon, is home to the body's largest and most diverse microbial community. The host and its commensal microbiota have evolved a mutualistic interdependency that significantly contributes to many aspects of the host's normal physiology, ranging from metabolism, to resisting pathogen colonization (Dethlefsen et al., 2007), to shaping and maintaining the host's immune system (Belkaid and Hand, 2014). The host, in turn, provides its microbiota with nutrients and environments suitable for growth. Even so, not all microbes are able to colonize and/or flourish in a given host, as the availability of specific nutrients controls the abundance of certain microbes (Pereira and Berry, 2017). The ability to acquire and utilize nutrients is thus essential for commensal microbes to stably colonize their host.

Despite this coevolved mutualism, the mucosal immune system must still prevent microorganisms, be they commensals or pathogens, from disseminating beyond mucosal surfaces. On this front, iron sequestration by the host represents a conserved innate immune mechanism for limiting microbial growth. Nevertheless, pathogens have evolved strategies to circumvent these defenses. Here we provide an overview of mechanisms underpinning the tug-of-war for iron between microbes and their host, which ultimately determines the health of the host and the survival of pathogenic microbes.

\section{Iron regulation in humans}

Regulation of iron metabolism is a balance of iron absorption, recycling, and loss. Iron levels must be tightly controlled to avoid iron deficiency (which can result in anemia) and to prevent toxicity due to excess iron. Trafficking and systemic metabolism of iron have been the subject of excellent reviews (e.g., (Hentze et al., 2010)). In this section, we provide a brief synopsis. Dietary iron is generally acquired as heme or non-heme iron, and is absorbed in the duodenum and proximal jejunum (Hentze et al., 2010). Whereas heme iron is efficiently absorbed, likely via receptor-mediated endocytosis, non-heme iron (typically ferric iron) has a much lower bioavailability (approximately 10\%). In the duodenum, insoluble ferric iron $\left(\mathrm{Fe}^{3+}\right)$ is reduced to the soluble ferrous $\left(\mathrm{Fe}^{2+}\right)$ form by ferric reductases including duodenal cytochrome $\mathrm{b}$ (DCYTB). Ferrous iron is then taken up by various iron transporters, including its primary transporter DMT1 (also known as NRAMP2). Absorbed iron is either utilized by enterocytes, where it is stored in association with ferritin, or released into the plasma via the basolateral export protein ferroportin (FPN1). Once in the plasma, iron is complexed with transferrin (Tf), then distributed to target organs and cells 
such as erythroid precursor cells (Hentze et al., 2010). Of important note, humans lack a discrete mechanism for excreting surplus iron from the body, so the body's total iron content is solely regulated at the level of intestinal absorption. Dietary iron absorption and distribution throughout the body are governed by the liver hormone hepcidin, the master regulator of iron homeostasis (Drakesmith and Prentice, 2012). In addition to maintaining a healthy level of iron in the body, hepcidin is also leveraged by the immune system to fight infection. One of the first acute phase responses following an infectious and/or inflammatory insult is the substantial and rapid decrease of plasma iron. This process, known as hypoferremia of inflammation, is cytokine-driven and results in the upregulation of hepcidin, which reduces intestinal iron absorption and promotes systemic iron sequestration (Soares and Weiss, 2015).

Unabsorbed dietary iron (primarily heme and ferric iron) passes from the small intestine into the colon, where it can be scavenged by the microbiota and by pathogens. Indeed, several studies have shown that dietary iron and iron fortification can impact the composition of the microbiota as well as increase susceptibility to enteric pathogens (e.g., (Jaeggi et al., 2015)). This is particularly relevant in patients with inflammatory bowel disease (IBD) who develop anemia (Werner et al., 2011), and is discussed in a section further below. Beyond nourishing intestinal microbes, dietary iron can also have a profound impact on host physiology and on bacterial pathogenesis at extraintestinal sites (reviewed in (Lopez and Skaar, 2018)). Of note, as iron uptake primarily occurs in the proximal small intestine, patients that have their colon resected (colectomy) exhibit normal systemic iron levels, unless complications arise. For example, pouchitis is a complication resulting from the ileal pouch-anal anastomosis created during colectomy of UC patients (Ferrante et al., 2008). Recent studies have established a role for the microbiota in the pathophysiology of pouchitis (Machiels et al., 2017), and the administration of a probiotic cocktail has been shown to be effective in preventing onset and relapses of the disease (Gionchetti et al., 2012; Mimura et al., 2004). Whether and how iron impacts the development of pouchitis remains to be established.

\section{Iron limitation at mucosal surfaces during health and disease}

A number of mechanisms contribute to defense at mucosal surfaces, including colonization resistance mediated by the microbiota (Sassone-Corsi and Raffatellu, 2015) and microbial growth restriction mediated by nutritional immunity (Hood and Skaar, 2012). Iron represents an important battleground in both of these processes as it is a key nutrient that must be scavenged from the host environment by commensals and by pathogens. On the host side, intestinal homeostasis and restriction of pathogen growth at mucosal surfaces are, in part, accomplished by the secretion of potent metal-chelating proteins.

Lactoferrin (Lf), a widely conserved protein belonging to the transferrin family, contains two binding sites for ferric iron that enable tight but reversible iron sequestration (Ward and Conneely, 2004). A variety of functions are attributable to Lf, ranging from antimicrobial activities to iron-independent, immunomodulatory roles (Kruzel et al., 2017; Ward and Conneely, 2004). Lf's antimicrobial activity is thus far based on two characterized properties: (i) its strong iron-binding capacity; (ii) its high affinity for lipopolysaccharide (LPS). While predominantly found in milk, $\mathrm{Lf}$ is also present in mucosal secretions 
including tears as well as bronchial and vaginal mucus (Levay and Viljoen, 1995). Lf is also an important component of neutrophil secondary granules and can bind to iron at a low $\mathrm{pH}$, a trait that might be beneficial in inflammatory and infectious foci, which are often more acidic.

In addition to directly inhibiting pathogen growth in vitro, Lf can also promote colonization resistance and general health through shaping the microbiota. A newborn's immune system is immature and thus infants are at higher risk of infection. This susceptibility is partly compensated for by passive transfer of maternal antibodies through the placenta and by ingestion of human milk. In the latter context, Lf in human milk appears to beneficially modulate the neonatal microbiota composition. Although the antimicrobial effects of Lf are well supported by in vitro studies, the in vivo role of Lf against pathogens is less well defined (Sánchez et al., 1992). Nevertheless, evidence indicates that Lf promotes the growth of beneficial bacteria with low iron requirements, including intestinal and vaginal Lactobacillus spp. (Vega-Bautista et al., 2019). Moreover, Lf has been shown to promote the growth of probiotic strains belonging to the genus Bifidobacterium, which are among the first anaerobes to colonize and predominate the gut of breast-fed infants, although this effect might be attributable to roles associated with both the iron-bound and the iron-free forms of Lf (Vega-Bautista et al., 2019).

Lipocalin-2 (Lcn2; also known as neutrophil gelatinase-associated lipocalin [NGAL], siderocalin, or 24p3) is a small glycoprotein secreted by myeloid and epithelial cells in an interleukin-22-dependent manner upon infection and inflammation (Flo et al., 2004;

Raffatellu et al., 2009). Lcn2's antimicrobial properties derive primarily from its ability to bind to a subset of bacterial siderophores, small molecules that are produced by bacteria to scavenge iron (described further in Section 4.1). One such siderophore is enterobactin, which is produced by commensal and pathogenic Gram-negative bacteria belonging to the family Enterobacteriaceae. By binding to enterobactin, Lcn2 limits bacterial iron acquisition and subsequently hampers the growth of enterobactin-dependent microbes (Figure 1) (Flo et al., 2004). In addition to siderophore binding, Lcn 2 also exhibits activities that include inducing cytokines, mediating the recruitment of inflammatory cells, promoting apoptosis, and T-cell priming (Moschen et al., 2017).

Calprotectin (CP; a heterodimer of the S100A8 and S100A9 proteins) is another antimicrobial host product with metal-chelating properties. Although $\mathrm{CP}$ has been widely characterized for its roles in scavenging zinc and manganese (Corbin et al., 2008), recent in vitro studies indicate that $\mathrm{CP}$ can also chelate $\mathrm{Fe}^{2+}$ (Nakashige et al., 2015) and induce $\mathrm{Fe}$ starvation in Pseudomonas aeruginosa and Acinetobacter baumannii (Wang et al., 2019; Zygiel et al., 2019), however an in vivo context for these findings remains to be described. Neutrophils are the main source of CP, and release it at sites of infection (Corbin et al., 2008). Similar to Lf and Lcn2, fecal CP correlates with disease activity in patients with Crohn's disease and ulcerative colitis (Zollner et al., 2020), and is thus frequently utilized to aid in the diagnosis and monitoring of patients with IBD (Sipponen et al., 2008).

In addition to the iron-binding proteins produced by the host, members of the commensal microbiota can also play a key role in limiting iron availability to pathogens. For example, 
the probiotic bacterium E. coli Nissle $1917(\mathrm{EcN})$ deploys multiple iron acquisition systems to compete with pathogens in iron-limited environments such as the inflamed gut (Deriu et al., 2013).

\section{Microbial iron metabolism, with a focus on Gram-negative bacteria}

With the exception of some non-pathogenic lactic acid bacteria and the Lyme disease pathogen Borrelia burgdorferi, most microorganisms rely on micromolar iron concentrations for metabolism and replication(Archibald, 1983; Posey and Gherardini, 2000; Weinberg, 1978). However, iron in the mammalian host is largely bound to host proteins (e.g., ferritin, Tf, Lf, hemoproteins), thereby reducing iron's toxicity and accessibility. As such, microbes have evolved a variety of iron acquisition strategies to colonize iron-limited niches within the host, with some bacteria even being able to reside within intracellular compartments. Microbial iron acquisition mechanisms include the secretion and uptake of siderophores, and the import of host-derived Tf and heme. Many mechanisms of bacterial iron homeostasis are regulated at the transcriptional level. Under iron-rich conditions, iron-acquisition mechanisms are repressed by Fur, the ferric uptake regulator. Fur is a global iron regulator in many characterized Gram-negative (e.g., enterobacteria) and some Gram-positive (e.g., Bacillus spp.) bacteria (Miethke and Marahiel, 2007). The diphtheria toxin regulator DtxR plays a comparable role in many characterized Gram-positive bacteria with a high genomic GC content (e.g., corynebacteria, mycobacteria) (Miethke and Marahiel, 2007). In Gramnegative bacteria, TonB-dependent receptor complexes play a key role for energizing the transport of iron across the bacterial outer membrane via various uptake systems for siderophores, heme, or Tf/Lf, among others (Krewulak and Vogel, 2008; Noinaj et al., 2010). Nevertheless, much like mammals, iron overload can be toxic to bacteria, which is why iron assimilation is tightly regulated. Therefore, the mechanisms described below are generally expressed in iron-limiting conditions.

\subsection{Siderophore-based iron acquisition systems}

Many bacterial species, including members of the microbiota and various human pathogens, secrete structurally diverse, high-affinity, iron-chelating molecules known as siderophores (Figure 2a) (Crosa, 1989). For many Gram-negative bacteria, siderophores are essential virulence factors. Enterobactin, a catecholate-type siderophore, and the related siderophore salmochelin, a C-glucosylated derivative of enterobactin, are the most common siderophores utilized by enterobacteria such as E. coli, Klebsiella spp., and Salmonella enterica (Figure 1) (Raymond et al., 2003). Other siderophores include yersiniabactin (produced by Yersinia pestis and $Y$. enterocolitica, but also by other Enterobacteriaceae including E. coli and Klebsiella), aerobactin (E. coli), and vibriobactin (Vibrio cholerae) (Miethke and Marahiel, 2007). Of note, in a process termed 'iron piracy', some bacterial species are capable of acquiring siderophores that they do not synthesize, generally termed xenosiderophores (e.g., Salmonella and Yersinia acquire, but do not make, ferrioxamine). Moreover, a subset of these bacteria do not produce siderophores at all (e.g., Bacteroides thetaiotaomicron does not produce siderophores, but can acquire enterobactin and salmochelin) (Figure 3b) (Zhu et al., 2020). As the biosynthesis of siderophores is an energy-intensive process, iron piracy via xenosiderophores is a lucrative iron-acquisition mechanism for the non-producing strains. In 
addition to bacteria, fungi also produce and uptake siderophores. For reference, in 1952, the fungal siderophores ferrichrome and coprogen were among the first siderophores to be described (Hesseltine et al., 1952; Neilands, 1952). Furthermore, several fungal species including Candida spp. and Saccharomyces spp. engage in iron piracy by importing xenosiderophores (Almeida et al., 2009; Winkelmann, 2007).

During iron limitation, microbes release siderophores into the environment to capture iron. Importantly, siderophores' high affinity for ferric iron enables them to outcompete host proteins (e.g., Tf) for this metal (Caza and Kronstad, 2013). To recover the captured iron, Gram-negative bacteria express outer membrane receptors that import iron-laden siderophores in a TonB-dependent fashion. The evolutionary importance of siderophores is reflected by the co-evolution of siderophore neutralization strategies by mammals. As discussed in Section 3, the host antimicrobial protein Lcn2 efficiently neutralizes bacterial enterobactin; accordingly, $L c n 2$-deficient mice are highly susceptible to infection with microbes that utilize enterobactin for iron acquisition (Flo et al., 2004; Moschen et al., 2016). However, many bacterial pathogens circumvent Lcn2-mediated enterobactin sequestration by producing salmochelin, a chemically modified form of enterobactin that cannot be bound by Lcn2 (Fischbach et al., 2006; Raffatellu et al., 2009). Thus, salmochelin and other "stealth siderophores" enable pathogens to evade host nutritional immunity (Figure 1 and Figure 2b).

\subsection{Heme acquisition systems}

Heme is comprised of an iron ion bound to a porphyrin ring. Most of the heme in humans is associated with intracellular metalloproteins (hemoproteins) including hemoglobin, myoglobin, and cytochromes. Many bacterial pathogens have evolved specific mechanisms to liberate heme from vertebrate hemoproteins (Runyen-Janecky, 2013). Moreover, although free heme is limited and usually scavenged by host hemopexin or serum albumin, small amounts can become available to microbes, for example from lysed erythrocytes or from host cells damaged during infection (Runyen-Janecky, 2013). In the gut, dietary heme represents another source of iron that can be utilized by intestinal bacteria (Figure 2). In Gram-negative bacteria, general mechanisms of heme acquisition involve receptors that directly bind heme or hemoproteins (e.g., hemoglobin, hemopexin, haptoglobin) or involve scavenging and uptake of heme via bacterial hemophores (Runyen-Janecky, 2013). Heme is then internalized across the outer membrane via TonB-dependent transport, after which it is brought across the cytoplasmic membrane by $\mathrm{ABC}$ transporters. Once heme arrives in the cytoplasm, specific heme oxygenases cleave the porphyrin ring to release the iron (RunyenJanecky, 2013).

One example of a Gram-negative pathogen that relies on heme for its growth is the "hemeloving" opportunistic human pathogen Haemophilus influenzae, which colonizes the upper respiratory tract and is a frequent cause of pneumonia, otitis, and meningitis. The ironlimited host environment triggers the pathogen to express several heme acquisition systems (Hup, HgpA, HgpB, HgpC, HxuA, HxuC), which in turn mediate acquisition of heme directly and from various hemoproteins (Runyen-Janecky, 2013). 
Alternative bacterial strategies to obtain iron from heme include secreting hemolysins to lyse red blood cells or producing proteases that degrade hemoglobin. Such mechanisms are employed by several Gram-negative pathogens including pathogenic E. coli, V. cholerae, and Bordetella pertussis, as well as by the Gram-positive pathogen Staphylococcus aureus (Caza and Kronstad, 2013).

Heme uptake is also employed by certain fungal pathogens (Bairwa et al., 2017). The polymorphic fungus and opportunistic pathogen Candida albicans can be part of the commensal microbiota and inhabit the oral cavity, the GI tract, and/or the female reproductive tract. In most individuals, $C$. albicans is harmless because it is kept under control by the microbiota through nutrient competition. However, under circumstances such as immunodeficiency, antibiotic treatment, or immunosuppressive therapy, $C$. albicans can cause diseases ranging from cutaneous infections to life-threatening systemic candidiasis (Mayer et al., 2013). In addition to xenosiderophore uptake, C. albicans also relies on iron acquisition via heme/hemoglobin (Bairwa et al., 2017).

\subsection{Transferrin/lactoferrin receptor-based systems}

The iron-carrying host glycoproteins $\mathrm{Tf}$ and $\mathrm{Lf}$ exhibit structural similarities, and this is reflected in the similarities of bacterial Tf and Lf receptors (Gray-Owen and Schyvers, 1996). Tf in the serum is primarily exploited as a source of iron by pathogens during bloodstream or systemic infections, whereas $\mathrm{Lf}$ is generally leveraged by pathogens at mucosal surfaces (Morgenthau et al., 2013). Tf and Lf can be exploited by pathogens expressing bacterial outer membrane receptors including transferrin-binding-protein $\mathrm{A}$ and $\mathrm{B}(\mathrm{TbpAB})$ and lactoferrin-binding-protein A and B (LbpAB), respectively (Morgenthau et al., 2013). Both uptake systems function in a similar fashion in that the receptors remove ferric iron from $\mathrm{Tf}$ or $\mathrm{Lf}$, and then transport the iron across the outer membrane in a TonBdependent manner (Caza and Kronstad, 2013; Morgenthau et al., 2013). The specific mechanisms and the order of the steps, however, remain to be elucidated. The utilization of $\mathrm{Tf}$ or $\mathrm{Lf}$ as iron sources has been described for important human pathogens including Neisseria spp. and Helicobacter pylori (Caza and Kronstad, 2013; Morgenthau et al., 2013).

\section{Regulation of mucosal iron metabolism during infection and inflammation}

Mucosal surfaces including the eyes and oropharynx, as well as the GI, respiratory, and urogenital tracts, use various antimicrobial defense strategies that interfere with microbial adhesion and survival. Among these defenses is the upregulation of Lf and Lcn2. Although both host proteins play additional roles in other cells and body sites (Kruzel et al., 2017; Moschen et al., 2017), here we focus on their roles at mucosal surfaces.

\subsection{Iron metabolism during intestinal inflammation}

The lower GI tract is a complex ecosystem and harbors the most abundant and diverse microbial community of the human body (Huttenhower et al., 2012). The commensal gut microbiota is dominated by anaerobic microbes that mainly belong to the phyla Firmicutes and Bacteroidetes. E. coli and other Enterobacteriaceae family members (belonging to the 
phylum Proteobacteria) typically comprise a minor fraction of the microbiota in the noninflamed gut. One of the main mechanisms by which beneficial commensal microbes prevent the outgrowth of potentially harmful microbes is through the competition for iron. In the healthy gut, commensal microbes consume available micronutrients and heme, which provides an ideal environment for the microbiota to reside in. In turn, the gut microbiota provides a variety of beneficial metabolites to the host, such as B vitamins (Celis and Relman, 2020). This mutual relationship between the host and commensal microbes makes it difficult for pathogens to become established in these densely colonized host compartments (Vonaesch et al., 2018) (Figure. 3a).

Numerous intrinsic and extrinsic factors modulate the microbiota's composition. For example, intestinal inflammation (regardless of etiology) and antibiotic administration have a major impact on the microbiota which is typified by a decrease in microbial diversity (Bäumler and Sperandio, 2016). The inflamed gut exhibits an altered nutritional environment, generated in part by host-mediated iron limitation (Deriu et al., 2013; Raffatellu et al., 2009) (Figure 2b). Gut inflammation is also frequently associated with the loss of Bacteroidetes and Firmicutes in favor of a bloom of Gammaproteobacteria (usually members of the Enterobacteriaceae, Figure 3c) (Baumler and Sperandio, 2016). Overall, the observed decreases in microbial diversity generally lead to, and sometimes overtly favor, pathogen outgrowth. Lcn 2 is highly upregulated in the gut as part of the inflammatory response to restrict blooms of harmful microbes (Moschen et al., 2016; Raffatellu et al., 2009), for instance during chronic intestinal inflammation. In this context, Lcn2 greatly prevented the exacerbation of colitis and spontaneous colonic tumor formation by impeding the growth of enterobactin-utilizing, pro-colitogenic bacterial species in mice (Figure 3c) (Moschen et al., 2016). Nevertheless, some successful enterobacterial pathogens, including Salmonella, Klebsiella and pathogenic E. coli, circumvent Lcn2-mediated iron restriction by secreting stealth siderophores including salmochelin, which cannot be sequestered by Lcn2 (Figure 2b) (Bachman et al., 2012; Fischbach et al., 2006; Flo et al., 2004; Raffatellu et al., 2009).

It is worth noting that Lcn2 can also restrict the growth of enterobactin-secreting commensal bacteria (Figure $2 \mathrm{~b}$ ). However, certain members of the commensal microbiota have, similar to pathogens, evolved resistance to some host antimicrobial responses. For example, beneficial species including EcN, Bifidobacterium spp., and Lactobacillus spp. exhibit some resistance to host-mediated iron limitation (Deriu et al., 2013; Vega-Bautista et al., 2019). Intriguingly, the aforementioned microbes have been administered as probiotics for a long time, despite the mechanistic basis of their beneficial properties being unknown. Recent studies, however, have shed light on some of these mechanisms. The probiotic EcN employs multiple systems to acquire iron from the intestinal environment, including multiple siderophores (enterobactin, yersiniabactin, aerobactin, salmochelin) (Valdebenito et al., 2006). These mechanisms of iron acquisition collectively increase EcN's ability to compete with other microbes, including Salmonella, during colitis (Deriu et al., 2013) (Figure 3b). Siderophore cross-feeding between different bacterial taxa offers another mechanism for commensals to obtain iron. For example, B. thetaiotaomicron, a member of the phylum Bacteroidetes, pirates xenosiderophores from commensal and pathogenic Enterobacteriaceae 
(phylum Proteobacteria) in the inflamed gut, thereby contributing to the resilience of the commensal gut microbiota (Zhu et al., 2020) (Figure 3b).

Some studies in model organisms have proposed that the host might benefit from microbeassociated iron metabolism and sensing. A study by Qi et al. demonstrated that enterobactin produced by commensal E. coli increased mitochondrial iron levels and promoted growth of the worm Caenorhabditis elegans (Qi and Han, 2018). Another study reported that intestinal commensals such as Lactobacillus spp. can sense levels of iron in the gut and subsequently modulate the host's systemic iron metabolism. Here, microbe-derived metabolites suppressed the host transcription factor HIF-2 $a$ and increased the expression of ferritin, thereby reducing systemic iron overload in an experimental model of hemochromatosis (Das et al., 2020). The microbiota has also been shown to modulate host expression of hepcidin in the gut (Bessman et al., 2020). In this study, commensal microbes were shown to induce hepcidin expression in dendritic cells, which in turn promoted iron sequestration by macrophages. In addition to modulating gut microbiota composition, this process also contributed to mucosal healing in an experimental IBD model (Bessman et al., 2020).

\subsection{Iron in the context of inflammatory bowel disease}

IBD, including Crohn's disease (CD) and ulcerative colitis (UC), comprises a heterogeneous spectrum of chronic and/or relapsing episodes of intestinal inflammation. Alterations of the gut microbiota and microbial interactions with the perturbed mucosal barrier are prominent features of IBD (Caruso et al., 2020). The inflamed gut mucosa is also responsible for chronic GI blood loss and reduced intestinal iron absorption, which is frequently accompanied by iron deficiency and anemia of chronic disease (Nielsen et al., 2018). Iron supplementation in anemic IBD patients, however, differs from standard approaches, and several considerations need to be taken into account (outlined in (Nielsen et al., 2018)).

In animal models of IBD, it has been shown that high concentrations of luminal iron or heme iron alter gut microbial communities, further exacerbating the bloom of Gammaproteobacteria and worsening colitis (Constante et al., 2017; Mahalhal et al.; Werner et al., 2011) (Figure 3c). Importantly, these effects were only observed when iron was administered orally, whereas intravenous iron did not induce such changes. These findings are in line with a study in IBD patients, showing that oral iron therapy is associated with distinct and unfavorable changes in gut microbial ecology (Lee et al., 2017).

In stark contrast to these findings, a recently published study demonstrated that a short course of dietary iron supplementation attenuated the virulence of an enteric pathogen (Sanchez et al., 2018). Following infection of mice with the murine pathogen Citrobacter rodentium, a common model for human enteropathogenic E. coli (EPEC) and enterohemorrhagic E. coli (EHEC) infections, dietary iron supplementation promoted host survival by increasing intestinal glucose content and insulin resistance. Elevated glucose resulted in suppression of virulence factors in the pathogen, which resulted in the pathogen colonizing, but not killing, its host. This phenomenon was termed a 'cooperative response' by the authors (Sanchez et al., 2018). Although iron supplementation during infection has previously been shown to be detrimental to humans and model organisms by promoting the growth of pathogens, it is possible that oral iron supplementation may promote such a 
cooperative response in some contexts of localized infection or microbiota composition. Future studies are needed to show whether this result applies to other microbes and in the context of other hosts.

In patients with ileal $\mathrm{CD}$, a distinct pathovar of $E$. coli is abnormally prevalent. Termed adherent-invasive E. coli (AIEC), these mucosa-associated bacteria are able to adhere to and invade intestinal epithelial cells, a process that likely contributes to the progression of CD (Shaler et al., 2019). In addition to other virulence factors, iron metabolism likely plays a key role in AIEC's pathogenicity (Figure 3c). Iron acquisition systems that are most frequently found in pathogenic Enterobacteriaceae, such as the synthesis and uptake of yersiniabactin and salmochelin, are present in many AIEC strains. Moreover, the presence of a heme acquisition system correlates with AIEC's intracellular persistence in macrophages (Dogan et al., 2014). Notably, there are currently no treatments available that specifically eradicate CD-associated AIEC from the gut of these patients. Although the gut microbiota plays a key role in the pathogenesis of IBD, current standard treatments focus on targeting the immune system rather than the intestinal microbiota. Routine administration of antibiotics in IBD patients remains controversial because it further disrupts the gut microbiota, promoting bacterial dysbiosis. Moreover, antibiotics have been linked to potentiating AIEC infection and outgrowth (Shaler et al., 2019). Thus, antimicrobial strategies that selectively target pathogenic Enterobacteriaceae in IBD are highly desirable. Because iron metabolism is an important virulence factor for IBD-associated bacteria, developing strategies to impede pathogenic iron metabolism could be useful.

\section{Iron metabolism in the respiratory and genito-urinary tract}

\subsection{The respiratory tract}

Bacterial communities of the respiratory tract are more dynamic, albeit less well characterized, than those of the gut (Huffnagle et al., 2017). Similar to the gut, however, iron acquisition is also important for bacterial pathogens that infect the airways.

Correspondingly, Lcn2 is also highly upregulated in human pulmonary tissue during bacterial pneumonia (Warszawska et al., 2013). However, whether this increased expression of Lcn2 results in beneficial or detrimental outcomes strongly depends on the pathogen. The Gram-negative pathogen Klebsiella pneumoniae is a common cause of bacterial pneumonia and sepsis. Clinical isolates of $K$. pneumoniae have been shown to either produce enterobactin alone, or a combination of enterobactin, salmochelin, and yersiniabactin (Bachman et al., 2011). Whereas salmochelin and yersiniabactin enabled $K$. pneumoniae isolates to evade Lcn2-mediated iron sequestration and to disseminate systemically, Lcn2 conferred substantial protection against isolates that only produce enterobactin (Bachman et al., 2012). Of note, siderophores in this context also exhibited a noncanonical role by acting directly on the host to induce inflammatory cytokines (Holden et al., 2016). In contrast to $K$. pneumoniae, the Gram-positive pathogen Streptococcus pneumoniae, the most prevalent bacterial cause of respiratory tract infections, acquires iron via hemoproteins instead of siderophores. Furthermore, instead of helping the host, increased Lcn2 expression worsened the outcome of $S$. pneumoniae infection by skewing macrophage polarization towards an anti-inflammatory phenotype (Warszawska et al., 2013). The differing impact of Lcn2 in 
these examples highlights the protein's context-dependent roles during infection, which stem from its siderophore-neutralizing and immunomodulatory properties.

Increased iron levels have been observed in the sputum of patients with the chronic pulmonary disease cystic fibrosis (CF), which has implications for a range of CF-related bacterial and fungal pathogens (Tyrrell and Callaghan, 2016). For example, Pseudomonas aeruginosa is a frequent cause of $\mathrm{CF}$ exacerbations, and studies have shown that this pathogen has a plethora of iron acquisition systems, including heme uptake and the production of siderophores such as pyoverdine and pyochelin (Minandri et al., 2016; Vasil and Ochsner, 1999).

\subsection{The genitourinary tract}

Similar to other mucosal sites, the genitourinary tract is colonized by microbes, although distinct differences exist between males and females (Gottschick et al., 2017). The healthy female vaginal microbiota is largely dominated by members of the lactic acid-producing bacteria Lactobacillus spp. (Huttenhower et al., 2012). These iron-independent commensals together with host-derived Lf represent essential factors to maintain a healthy vaginal environment. Bacterial vaginosis (BV) is a common disorder in women of reproductive age and is predominantly caused by Gardnerella vaginalis. Besides BV, G. vaginalis can also cause urinary tract infections (UTIs), amniotic infections, and pelvic inflammatory disease. Numerous iron-acquisition mechanisms have been shown for this pathogen, including siderophore and heme utilization as well as Lf uptake (Jarosik et al., 1998).

UTIs are another common infectious disease in otherwise healthy women, which is complicated by the rise of antimicrobial resistance. Uropathogenic E. coli (UPEC) is the primary cause of such infections, and iron acquisition gene clusters have been identified as important virulence factors to successfully colonize the urinary tract (Garcia et al., 2011; Mike et al., 2016). Lcn2 is secreted by the urinary tract mucosa of women with UTI and represents a colonization barrier that pathogens must overcome (Steigedal et al., 2014). UPEC is able to successfully colonize this environment by importing heme and by deploying the stealth siderophores salmochelin, yersiniabactin, and aerobactin (Garcia et al., 2011; Mike et al., 2016). In light of recent findings indicating the presence of a urinary tract microbiome (the so-called urobiome) (Wolfe and Brubaker, 2019), future studies may elucidate mechanisms of competition for iron between pathogens and the urobiome.

\section{Exploiting microbial iron acquisition for therapy and diagnosis}

As many pathogens require iron during infection, their means of iron acquisition constitute attractive therapeutic targets (Figure 4). For example, as described above, many pathogens require siderophores for iron uptake. As such, siderophore immunization might be a promising approach to limit microbial iron acquisition during infection. To this end, immunization against yersiniabactin and aerobactin in the context of UTIs protected from systemic infection with UPEC (Figure 4a) (Mike et al., 2016). Similarly, immunization with the siderophore enterobactin, which resulted in the production of antibodies against both enterobactin and salmochelin, protected against intestinal Salmonella infection (Figure 4a) (Sassone-Corsi et al., 2016a). Intriguingly, the reduced Salmonella burden in enterobactin- 
immunized mice was paralleled by increased levels of Lactobacillus spp. This could be due to a growth advantage of Lactobacillus over other commensals in the inflamed, irondeprived intestine, although the overall impact of enterobactin immunization on the gut microbiota warrants further investigation.

Another way to exploit siderophore-mediated iron acquisition is by employing "Trojan horse" antimicrobials, wherein an antimicrobial molecule is conjugated to a natural product that is taken up by the targeted microbe. Although such compounds can be generated in the lab, it is worth noting that siderophore-antibiotic conjugates exist in nature; these so-called sideromycins constitute important fitness factors as they mediate microbial competition in nutrient-limited environments (Braun et al., 2009). One class of sideromycins are the microcins, which are comprised of an antibacterial peptide that is covalently attached to a siderophore (Braun et al., 2009). By secreting microcins, $\mathrm{EcN}$ is able to inhibit the growth of enteric pathogens during intestinal inflammation without broadly affecting the gut microbiota (Figure 4a, panel II) (Sassone-Corsi et al., 2016b). Inspired by sideromycins that exhibit narrow-spectrum activity, researchers have generated synthetic siderophore-antibiotic conjugates with the goal of more specifically targeting pathogens. For example, conjugating enterobactin to the broad-spectrum antibiotic ciprofloxacin yielded a narrow-spectrum antibacterial compound. This molecule only targeted E. coli that express the salmochelin system's IroD esterase, an enzyme that hydrolyzes enterobactin and salmochelin, and is thus predicted to preferentially target pathogens instead of commensals (Neumann et al., 2018) (Figure 4b, panel I).

In addition to being a target for antimicrobial therapy, siderophores can be used directly as therapeutic and diagnostic agents. Desferrioxamine B (desferal), a siderophore naturally produced by Streptomyces spp., is an iron chelator approved for use in humans to treat iron overload syndromes. Siderophores are also being investigated for use in the molecular imaging of bacterial and fungal infections (Petrik et al., 2017) (Figure 4c). As a proof of principle, the Aspergillus siderophore triacetylfusarinine $\mathrm{C}$ was labeled with a positronemitting gallium radioisotope $\left({ }^{68} \mathrm{Ga}\right)$, then injected into mice and imaged by positron emission tomography (PET) to detect localization of the fungal pathogen Aspergillus fumigatus (Haas et al., 2015). This approach could be helpful to better diagnose and monitor infectious agents in complex disease scenarios.

\section{Conclusions}

With antimicrobial resistance posing an increasing threat to humans, alternative strategies to combat infections are in urgent need. As iron is a key micronutrient for most microbes, its abundance is tightly controlled by the host in order to restrict microbial growth. In addition to host-encoded mechanisms of iron sequestration, the microbiota also contributes to reduce iron availability to pathogens. Thus, to colonize the host, pathogens often deploy a variety of virulence factors that evade or subvert these iron-withholding mechanisms. Targeting microbial iron metabolism and virulence factors associated with iron acquisition hold promise as therapeutic strategies to reduce pathogen colonization and limit the severity of infection. Furthermore, such strategies could be advantageous for shifting the composition of the microbiota at mucosal surfaces by promoting the growth of beneficial microbes (e.g., 
Bifidobacterium and Lactobacillus spp.). These properties are particularly attractive in the context of diseases with underlying dysbiosis, including IBD. Collectively, iron metabolism at the host-microbe interface constitutes an important area for future investigations and for the potential development of novel therapeutics.

\section{Acknowledgements}

Work in MR lab is supported by Public Health Service Grants AI126277, AI114625, AI145325, by the Chiba University-UCSD Center for Mucosal Immunology, Allergy, and Vaccines, and by the UCSD Department of Pediatrics. M.R. also holds an Investigator in the Pathogenesis of Infectious Disease Award from the Burroughs Wellcome Fund. RRG was partly supported by a fellowship from the Max Kade Foundation and by a fellowship from the Crohn's and Colitis Foundation. Figures were created with BioRender.com

\section{References}

Almeida RS, Wilson D, and Hube B (2009). Candida albicans iron acquisition within the host. FEMS Yeast Res. 9, 1000-1012. [PubMed: 19788558]

Archibald F (1983). Lactobacillus plantarum, an organism not requiring iron. FEMS Microbiol. Lett. 19, 29-32.

Bachman MA, Oyler JE, Burns SH, Caza M, Lépine F, Dozois CM, and Weiser JN (2011). Klebsiella pneumoniae Yersiniabactin Promotes Respiratory Tract Infection through Evasion of Lipocalin 2. Infect. Immun. 79, 3309-3316. [PubMed: 21576334]

Bachman MA, Lenio S, Schmidt L, Oyler JE, and Weiser JN (2012). Interaction of Lipocalin 2, Transferrin, and Siderophores Determines the Replicative Niche of Klebsiella pneumoniae during Pneumonia. MBio 3.

Bairwa G, Jung WH, and Kronstad JW (2017). Iron acquisition in fungal pathogens of humans. Met. Integr. Biometal Sci. 9, 215-227.

Baumler AJ, and Sperandio V (2016). Interactions between the microbiota and pathogenic bacteria in the gut. Nature 535, 85-93. [PubMed: 27383983]

Belkaid Y, and Hand T (2014). Role of the Microbiota in Immunity and inflammation. Cell 157, 121141. [PubMed: 24679531]

Bessman NJ, Mathieu JRR, Renassia C, Zhou L, Fung TC, Fernandez KC, Austin C, Moeller JB, Zumerle S, Louis S, et al. (2020). Dendritic cell-derived hepcidin sequesters iron from the microbiota to promote mucosal healing. Science 368, 186-189. [PubMed: 32273468]

Braun V, Pramanik A, Gwinner T, Koberle M, and Bohn E (2009). Sideromycins: tools and antibiotics. Biometals 22, 3-13. [PubMed: 19130258]

Caruso R, Lo BC, and Núñez G (2020). Host-microbiota interactions in inflammatory bowel disease. Nat. Rev. Immunol. 1-16. [PubMed: 31792373]

Caza M, and Kronstad JW (2013). Shared and distinct mechanisms of iron acquisition by bacterial and fungal pathogens of humans. Front. Cell. Infect. Microbiol. 3.

Celis AI, and Relman DA (2020). Competitors versus Collaborators: Micronutrient Processing by Pathogenic and Commensal Human-Associated Gut Bacteria. Mol. Cell 78, 570-576. [PubMed: 32442503]

Constante M, Fragoso G, Calvé A, Samba-Mondonga M, and Santos MM (2017). Dietary Heme Induces Gut Dysbiosis, Aggravates Colitis, and Potentiates the Development of Adenomas in Mice. Front. Microbiol. 8.

Corbin BD, Seeley EH, Raab A, Feldmann J, Miller MR, Torres VJ, Anderson KL, Dattilo BM, Dunman PM, Gerads R, et al. (2008). Metal Chelation and Inhibition of Bacterial Growth in Tissue Abscesses. Science 319, 962-965. [PubMed: 18276893]

Crosa JH (1989). Genetics and molecular biology of siderophore-mediated iron transport in bacteria. Microbiol. Mol. Biol. Rev. 53, 517-530. 
Das NK, Schwartz AJ, Barthel G, Inohara N, Liu Q, Sankar A, Hill DR, Ma X, Lamberg O, Schnizlein MK, et al. (2020). Microbial Metabolite Signaling Is Required for Systemic Iron Homeostasis. Cell Metab. 31, 115-130.e6. [PubMed: 31708445]

Deriu E, Liu JZ, Pezeshki M, Edwards RA, Ochoa RJ, Contreras H, Libby SJ, Fang FC, and Raffatellu M (2013). Probiotic Bacteria Reduce Salmonella Typhimurium Intestinal Colonization by Competing for Iron. Cell Host Microbe 14, 26-37. [PubMed: 23870311]

Dethlefsen L, McFall-Ngai M, and Relman DA (2007). An ecological and evolutionary perspective on human-microbe mutualism and disease. Nature 449, 811-818. [PubMed: 17943117]

Dogan B, Suzuki H, Herlekar D, Sartor RB, Campbell BJ, Roberts CL, Stewart K, Scherl EJ, Araz Y, Bitar PP, et al. (2014). Inflammation-associated Adherent-invasive Escherichia coli Are Enriched in Pathways for Use of Propanediol and Iron and M-cell Translocation. Inflamm. Bowel Dis. 20, 1919-1932. [PubMed: 25230163]

Drakesmith H, and Prentice AM (2012). Hepcidin and the Iron-Infection Axis. Science 338, 768-772. [PubMed: 23139325]

Ferrante M, Declerck S, De Hertogh G, Van Assche G, Geboes K, Rutgeerts P, Penninckx F, Vermeire $\mathrm{S}$, and D'Hoore A (2008). Outcome after proctocolectomy with ileal pouch-anal anastomosis for ulcerative colitis. Inflamm. Bowel Dis. 14, 20-28. [PubMed: 17973304]

Fischbach MA, Lin H, Zhou L, Yu Y, Abergel RJ, Liu DR, Raymond KN, Wanner BL, Strong RK, Walsh CT, et al. (2006). The pathogen-associated iroA gene cluster mediates bacterial evasion of lipocalin 2. Proc. Natl. Acad. Sci. 103, 16502-16507. [PubMed: 17060628]

Flo TH, Smith KD, Sato S, Rodriguez DJ, Holmes MA, Strong RK, Akira S, and Aderem A (2004). Lipocalin 2 mediates an innate immune response to bacterial infection by sequestrating iron. Nature 432, 917-921. [PubMed: 15531878]

Garcia EC, Brumbaugh AR, and Mobley HLT (2011). Redundancy and specificity of Escherichia coli iron acquisition systems during urinary tract infection. Infect Immun 79, 1225-1235. [PubMed: 21220482]

Gionchetti P, Calafiore A, Riso D, Liguori G, Calabrese C, Vitali G, Laureti S, Poggioli G, Campieri M, and Rizzello F (2012). The role of antibiotics and probiotics in pouchitis. Ann. Gastroenterol. 25, 100-105. [PubMed: 24714229]

Gottschick C, Deng Z-L, Vital M, Masur C, Abels C, Pieper DH, and Wagner-Dobler I (2017). The urinary microbiota of men and women and its changes in women during bacterial vaginosis and antibiotic treatment. Microbiome 5, 99. [PubMed: 28807017]

Gray-Owen SD, and Schyvers AB (1996). Bacterial transferrin and lactoferrin receptors. Trends Microbiol. 4, 185-191. [PubMed: 8727598]

Haas H, Petrik M, and Decristoforo C (2015). An Iron-Mimicking, Trojan Horse-Entering Fungi-Has the Time Come for Molecular Imaging of Fungal Infections? PLoS Pathog. 11.

Hentze MW, Muckenthaler MU, Galy B, and Camaschella C (2010). Two to Tango: Regulation of Mammalian Iron Metabolism. Cell 142, 24-38. [PubMed: 20603012]

Hesseltine CW, Pidacks C, Whitehill AR, Bohonos N, Hutchings BL, and Williams JH (1952). Coprogen, a new growth factor for coprophilic fungi. J. Am. Chem. Soc. 74, 1362-1362.

Holden VI, Breen P, Houle S, Dozois CM, and Bachman MA (2016). Klebsiella pneumoniae Siderophores Induce Inflammation, Bacterial Dissemination, and HIF-1a Stabilization during Pneumonia. MBio 7.

Hood MI, and Skaar EP (2012). Nutritional immunity: transition metals at the pathogen-host interface. Nat. Rev. Microbiol. 10, 525-537. [PubMed: 22796883]

Huffnagle GB, Dickson RP, and Lukacs NW (2017). The respiratory tract microbiome and lung inflammation: a two-way street. Mucosal Immunol. 10, 299-306. [PubMed: 27966551]

Huttenhower C, Gevers D, Knight R, Abubucker S, Badger JH, Chinwalla AT, Creasy HH, Earl AM, FitzGerald MG, Fulton RS, et al. (2012). Structure, function and diversity of the healthy human microbiome. Nature 486, 207-214. [PubMed: 22699609]

Jaeggi T, Kortman GAM, Moretti D, Chassard C, Holding P, Dostal A, Boekhorst J, Timmerman HM, Swinkels DW, Tjalsma H, et al. (2015). Iron fortification adversely affects the gut microbiome, increases pathogen abundance and induces intestinal inflammation in Kenyan infants. Gut 64, 731-742. [PubMed: 25143342] 
Jarosik GP, Land CB, Duhon P, Chandler R, and Mercer T (1998). Acquisition of Iron by Gardnerella vaginalis. Infect. Immun. 66, 5041-5047. [PubMed: 9746616]

Krewulak KD, and Vogel HJ (2008). Structural biology of bacterial iron uptake. Biochim Biophys Acta Biomembr 1778, 1781-1804.

Kruzel ML, Zimecki M, and Actor JK (2017). Lactoferrin in a Context of Inflammation-Induced Pathology. Front. Immunol. 8, 1438. [PubMed: 29163511]

Lee T, Clavel T, Smirnov K, Schmidt A, Lagkouvardos I, Walker A, Lucio M, Michalke B, SchmittKopplin P, Fedorak R, et al. (2017). Oral versus intravenous iron replacement therapy distinctly alters the gut microbiota and metabolome in patients with IBD. Gut 66, 863-871. [PubMed: 26848182]

Levay PF, and Viljoen M (1995). Lactoferrin: a general review. Haematologica 80, 252-267. [PubMed: 7672721]

Lieu PT, Heiskala M, Peterson PA, and Yang Y (2001). The roles of iron in health and disease. Mol. Aspects Med. 22, 1-87. [PubMed: 11207374]

Liu Z, Ren Z, Zhang J, Chuang C-C, Kandaswamy E, Zhou T, and Zuo L (2018). Role of ROS and Nutritional Antioxidants in Human Diseases. Front. Physiol. 9, 477. [PubMed: 29867535]

Lopez CA, and Skaar EP (2018). The Impact of Dietary Transition Metals on Host-Bacterial Interactions. Cell Host Microbe 23, 737-748. [PubMed: 29902439]

Lozupone CA, Stombaugh JI, Gordon JI, Jansson JK, and Knight R (2012). Diversity, stability and resilience of the human gut microbiota. Nature 489, 220-230. [PubMed: 22972295]

Machiels K, Sabino J, Vandermosten L, Joossens M, Arijs I, Bruyn M. de, Eeckhaut V, Assche GV, Ferrante M, Verhaegen J, et al. (2017). Specific members of the predominant gut microbiota predict pouchitis following colectomy and IPAA in UC. Gut 66, 79-88. [PubMed: 26423113]

Mahalhal A, Williams JM, Johnson S, Ellaby N, Duckworth CA, Burkitt MD, Liu X, Hold GL, Campbell BJ, Pritchard DM, et al. Oral iron exacerbates colitis and influences the intestinal microbiome. 18.

Mayer FL, Wilson D, and Hube B (2013). Candida albicans pathogenicity mechanisms. Virulence 4, 119-128. [PubMed: 23302789]

Miethke M, and Marahiel MA (2007). Siderophore-Based Iron Acquisition and Pathogen Control. Microbiol. Mol. Biol. Rev. 71, 413-451. [PubMed: 17804665]

Mike LA, Smith SN, Sumner CA, Eaton KA, and Mobley HLT (2016). Siderophore vaccine conjugates protect against uropathogenic Escherichia coli urinary tract infection. Proc. Natl. Acad. Sci. 113, 13468-13473. [PubMed: 27821778]

Mimura T, Rizzello F, Helwig U, Poggioli G, Schreiber S, Talbot IC, Nicholls RJ, Gionchetti P, Campieri M, and Kamm MA (2004). Once daily high dose probiotic therapy (VSL\#3) for maintaining remission in recurrent or refractory pouchitis. Gut 53, 108-114. [PubMed: 14684584]

Minandri F, Imperi F, Frangipani E, Bonchi C, Visaggio D, Facchini M, Pasquali P, Bragonzi A, and Visca P (2016). Role of Iron Uptake Systems in Pseudomonas aeruginosa Virulence and Airway Infection. Infect. Immun. 84, 2324-2335. [PubMed: 27271740]

Morgenthau A, Pogoutse A, Adamiak P, Moraes TF, and Schryvers AB (2013). Bacterial receptors for host transferrin and lactoferrin: molecular mechanisms and role in host-microbe interactions. Future Microbiol. 8, 1575-1585. [PubMed: 24266357]

Moschen AR, Gerner RR, Wang J, Klepsch V, Adolph TE, Reider SJ, Hackl H, Pfister A, Schilling J, Moser PL, et al. (2016). Lipocalin 2 Protects from Inflammation and Tumorigenesis Associated with Gut Microbiota Alterations. Cell Host Microbe 19, 455-469. [PubMed: 27078067]

Moschen AR, Adolph TE, Gerner RR, Wieser V, and Tilg H (2017). Lipocalin-2: A Master Mediator of Intestinal and Metabolic Inflammation. Trends Endocrinol. Metab. 28, 388-397. [PubMed: 28214071]

Nakashige TG, Zhang B, Krebs C, and Nolan EM (2015). Human Calprotectin Is an Iron-Sequestering Host-Defense Protein. Nat. Chem. Biol. 11, 765-771. [PubMed: 26302479]

Neilands JB (1952). A Crystalline Organo-iron Pigment from a Rust Fungus (Ustilago sphaerogena)1. J. Am. Chem. Soc. 74, 4846-4847. 
Neumann W, Sassone-Corsi M, Raffatellu M, and Nolan EM (2018). Esterase-Catalyzed Siderophore Hydrolysis Activates an Enterobactin-Ciprofloxacin Conjugate and Confers Targeted Antibacterial Activity. J. Am. Chem. Soc. 140, 5193-5201. [PubMed: 29578687]

Nielsen OH, Soendergaard C, Vikner ME, and Weiss G (2018). Rational Management of IronDeficiency Anaemia in Inflammatory Bowel Disease. Nutrients 10, 82.

Noinaj N, Guillier M, Barnard TJ, and Buchanan SK (2010). TonB-dependent transporters: regulation, structure, and function. Annu. Rev. Microbiol. 64, 43-60. [PubMed: 20420522]

Pereira FC, and Berry D (2017). Microbial nutrient niches in the gut. Environ. Microbiol. 19, 13661378. [PubMed: 28035742]

Petrik M, Zhai C, Haas H, and Decristoforo C (2017). Siderophores for molecular imaging applications. Clin. Transl. Imaging 5, 15-27. [PubMed: 28138436]

Posey JE, and Gherardini FC (2000). Lack of a Role for Iron in the Lyme Disease Pathogen. Science 288, 1651-1653. [PubMed: 10834845]

Qi B, and Han M (2018). Microbial Siderophore Enterobactin Promotes Mitochondrial Iron Uptake and Development of the Host via Interaction with ATP Synthase. Cell 175, 571-582.e11. [PubMed: 30146159]

Raffatellu M, George MD, Akiyama Y, Hornsby MJ, Nuccio S-P, Paixao TA, Butler BP, Chu H, Santos RL, Berger T, et al. (2009). Lipocalin-2 Resistance Confers an Advantage to Salmonella enterica Serotype Typhimurium for Growth and Survival in the Inflamed Intestine. Cell Host Microbe 5, 476-486. [PubMed: 19454351]

Raymond KN, Dertz EA, and Kim SS (2003). Enterobactin: An archetype for microbial iron transport. Proc. Natl. Acad. Sci. 100, 3584-3588. [PubMed: 12655062]

Runyen-Janecky LJ (2013). Role and regulation of heme iron acquisition in gram-negative pathogens. Front. Cell. Infect. Microbiol. 3.

Sanchez KK, Chen GY, Schieber AMP, Redford SE, Shokhirev MN, Leblanc M, Lee YM, and Ayres JS (2018). Cooperative Metabolic Adaptations in the Host Can Favor Asymptomatic Infection and Select for Attenuated Virulence in an Enteric Pathogen. Cell 175, 146-158.e15. [PubMed: 30100182]

Sánchez L, Calvo M, and Brock JH (1992). Biological role of lactoferrin. Arch. Dis. Child. 67, 657661. [PubMed: 1599309]

Sassone-Corsi M, and Raffatellu M (2015). No Vacancy: How Beneficial Microbes Cooperate with Immunity To Provide Colonization Resistance to Pathogens. J. Immunol. 194, 4081-4087. [PubMed: 25888704]

Sassone-Corsi M, Chairatana P, Zheng T, Perez-Lopez A, Edwards RA, George MD, Nolan EM, and Raffatellu M (2016a). Siderophore-based immunization strategy to inhibit growth of enteric pathogens. Proc. Natl. Acad. Sci. U. S. A. 113, 13462-13467. [PubMed: 27821741]

Sassone-Corsi M, Nuccio S-P, Liu H, Hernandez D, Vu C, Takahashi ASA, Edwards RA, and Raffatellu M (2016b). Microcins mediate competition among Enterobacteriaceae in the inflamed gut. In Nature, $\mathrm{p}$.

Shaler CR, Elhenawy W, and Coombes BK (2019). The Unique Lifestyle of Crohn's DiseaseAssociated Adherent-Invasive Escherichia coli. J. Mol. Biol. 431, 2970-2981. [PubMed: 31029703]

Sipponen T, Savilahti E, Kolho K-L, Nuutinen H, Turunen U, and Fárkkilá M (2008). Crohn's disease activity assessed by fecal calprotectin and lactoferrin: correlation with Crohn's disease activity index and endoscopic findings. Inflamm. Bowel Dis. 14, 40-46. [PubMed: 18022866]

Soares MP, and Weiss G (2015). The Iron age of host-microbe interactions. EMBO Rep. 16, 14821500. [PubMed: 26474900]

Steigedal M, Marstad A, Haug M, Damas JK, Strong RK, Roberts PL, Himpsl SD, Stapleton A, Hooton TM, Mobley HLT, et al. (2014). Lipocalin 2 Imparts Selective Pressure on Bacterial Growth in the Bladder and Is Elevated in Women with Urinary Tract Infection. J. Immunol. Author Choice 193, 6081-6089.

Tyrrell J, and Callaghan M (2016). Iron acquisition in the cystic fibrosis lung and potential for novel therapeutic strategies. Microbiology 162, 191-205. [PubMed: 26643057] 
Valdebenito M, Crumbliss AL, Winkelmann G, and Hantke K (2006). Environmental factors influence the production of enterobactin, salmochelin, aerobactin, and yersiniabactin in Escherichia coli strain Nissle 1917. Int. J. Med. Microbiol. 296, 513-520. [PubMed: 17008127]

Vasil ML, and Ochsner UA (1999). The response of Pseudomonas aeruginosa to iron: genetics, biochemistry and virulence. Mol. Microbiol. 34, 399-413. [PubMed: 10564483]

Vega-Bautista A, de la Garza M, Carrero JC, Campos-Rodríguez R, Godínez-Victoria M, and DragoSerrano ME (2019). The Impact of Lactoferrin on the Growth of Intestinal Inhabitant Bacteria. Int. J. Mol. Sci. 20, 4101.

Vonaesch P, Anderson M, and Sansonetti PJ (2018). Pathogens, microbiome and the host: emergence of the ecological Koch's postulates. FEMS Microbiol. Rev. 42, 273-292. [PubMed: 29325027]

Wang J, Lonergan ZR, Gonzalez-Gutierrez G, Nairn BL, Maxwell CN, Zhang Y, Andreini C, Karty JA, Chazin WJ, Trinidad JC, et al. (2019). Multi-metal restriction by calprotectin impacts de novo flavin biosynthesis in Acinetobacter baumannii. Cell Chem. Biol. 26, 745-755.e7. [PubMed: 30905682]

Ward PP, and Conneely OM (2004). Lactoferrin: Role in iron homeostasis and host defense against microbial infection. Biometals 17, 203-208. [PubMed: 15222466]

Warszawska JM, Gawish R, Sharif O, Sigel S, Doninger B, Lakovits K, Mesteri I, Nairz M, Boon L, Spiel A, et al. (2013). Lipocalin 2 deactivates macrophages and worsens pneumococcal pneumonia outcomes. J. Clin. Invest. 123, 3363-3372. [PubMed: 23863624]

Weinberg ED (1978). Iron and infection. Microbiol. Rev. 42, 45-66. [PubMed: 379572]

Werner T, Wagner SJ, Martínez I, Walter J, Chang J-S, Clavel T, Kisling S, Schuemann K, and Haller D (2011). Depletion of luminal iron alters the gut microbiota and prevents Crohn's disease-like ileitis. Gut 60, 325-333. [PubMed: 21076126]

Winkelmann G (2007). Ecology of siderophores with special reference to the fungi. BioMetals 20, 379. [PubMed: 17235665]

Wolfe AJ, and Brubaker L (2019). Urobiome updates: advances in urinary microbiome research. Nat. Rev. Urol. 16, 73-74. [PubMed: 30510275]

Zhu W, Winter MG, Spiga L, Hughes ER, Chanin R, Mulgaonkar A, Pennington J, Maas M, Behrendt CL, Kim J, et al. (2020). Xenosiderophore Utilization Promotes Bacteroides thetaiotaomicron Resilience during Colitis. Cell Host Microbe 27, 376-388.e8. [PubMed: 32075741]

Zollner A, Schmiderer A, Reider SJ, Oberhuber G, Pfister A, Texler B, Watschinger C, Koch R, Effenberger M, Raine T, et al. (2020). Fecal biomarkers in inflammatory bowel diseases: calprotectin versus lipocalin-2 - a comparative study. J. Crohns Colitis.

Zygiel EM, Nelson CE, Brewer LK, Oglesby-Sherrouse AG, and Nolan EM (2019). The human innate immune protein calprotectin induces iron starvation responses in Pseudomonas aeruginosa. J. Biol. Chem. 294, 3549-3562. [PubMed: 30622135] 


\section{Enterobacteriaceae}

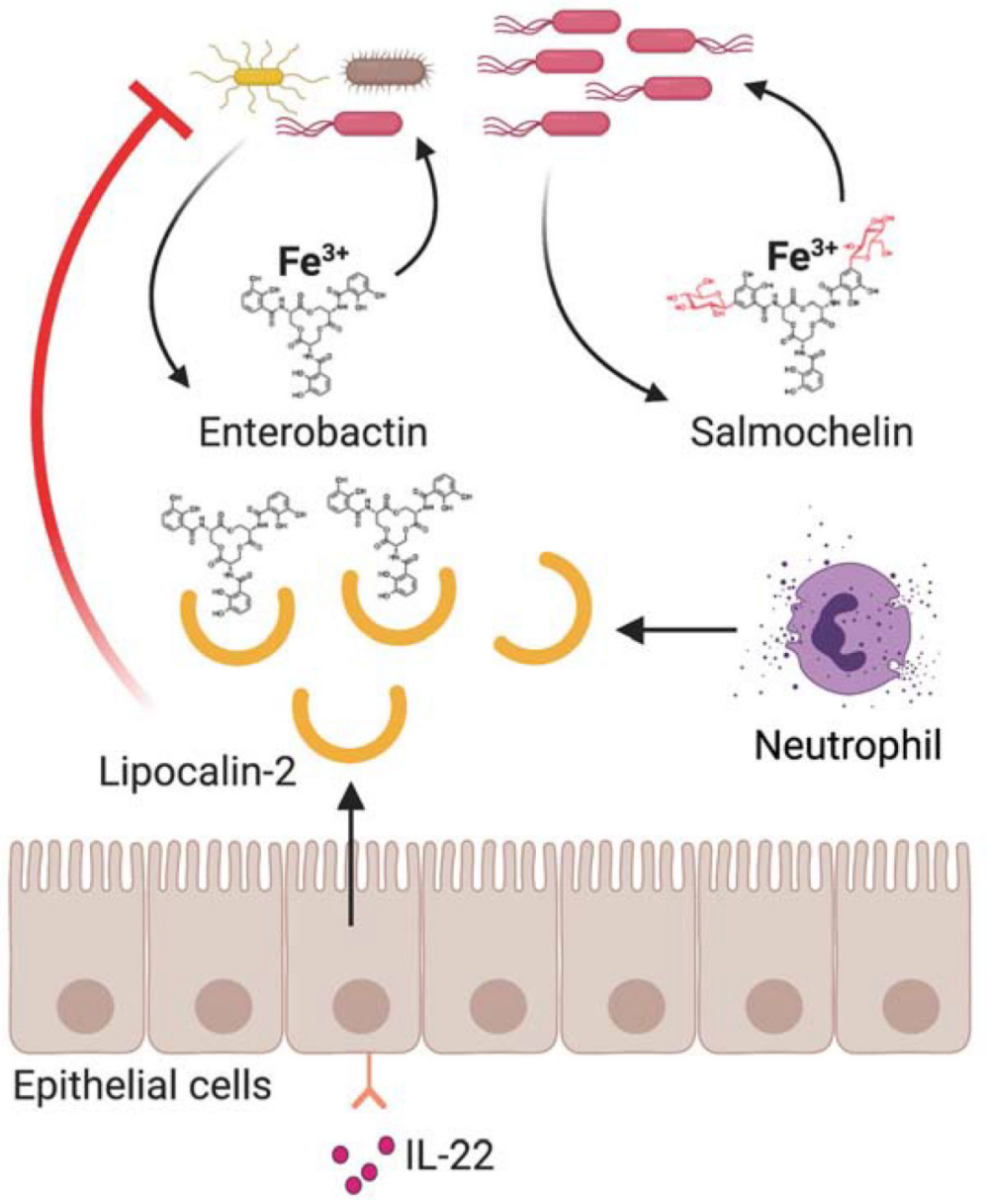

Figure 1. Evasion of Lcn2-mediated antimicrobial activity.

Members of the family Enterobacteriaceae can secrete siderophores such as enterobactin and salmochelin into the intestinal lumen to scavenge iron from the host environment. Some immune cells (e.g., neutrophils) and epithelial cells (in response to cytokines including interleukin-22) produce Lcn2, which sequesters enterobactin and thus limits the growth of enterobactin-dependent bacteria by depriving them of iron. In contrast, salmochelin and other 'stealth' siderophores enable certain bacteria (mostly pathogens) to evade Lcn2dependent iron limitation. 


\section{Homeostasis}

(a)

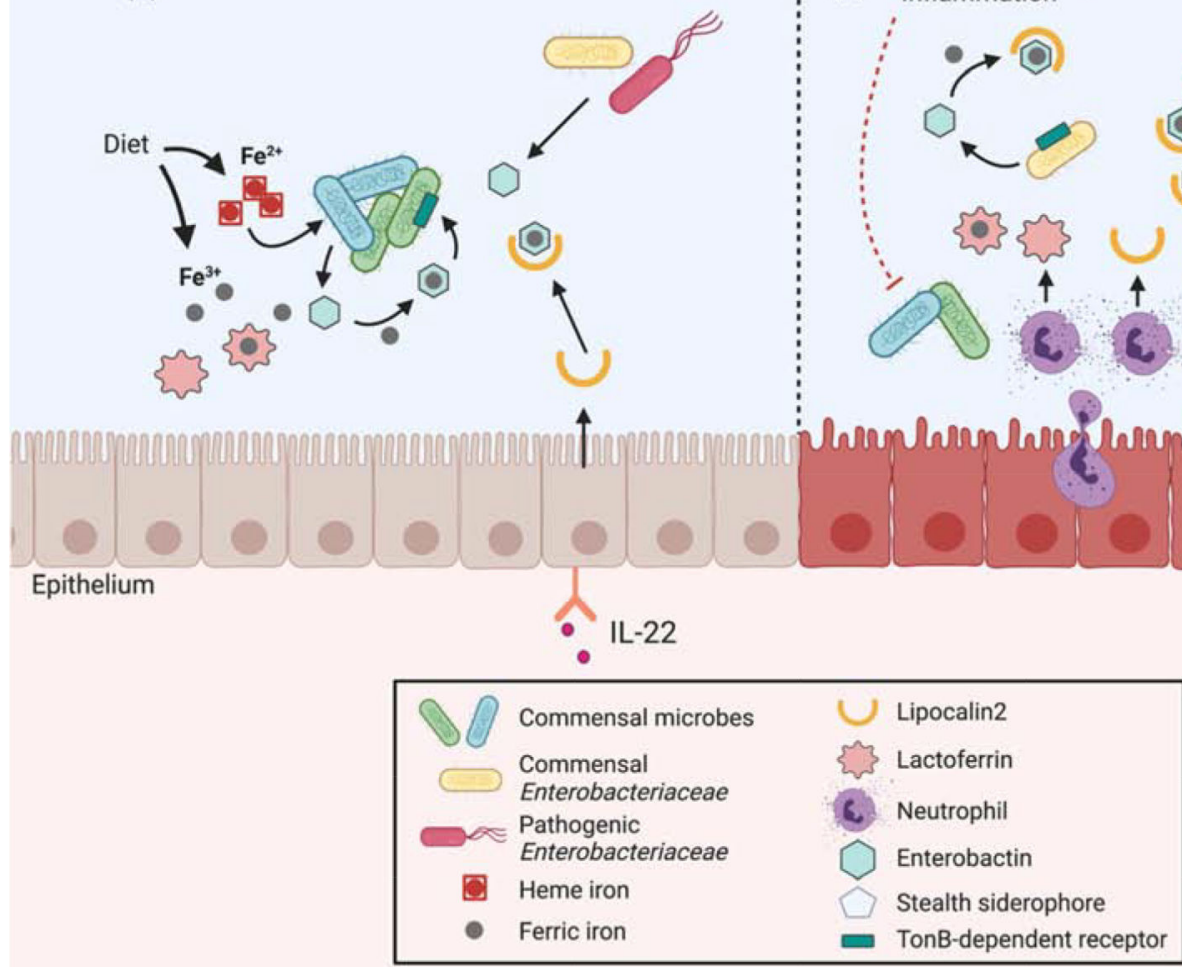

Figure 2. Model of host-microbe competition for iron in the gut during homeostasis and disease. (a) Under homeostatic conditions, members of the commensal microbiota acquire iron in the form of heme or by scavenging ferric iron with siderophores such as enterobactin. Low levels of antimicrobial proteins including lactoferrin (Lf) and lipocalin-2 (Lcn2) are present in the gut lumen. Lf sequesters luminal ferric iron, whereas Lcn2 sequesters iron-laden enterobactin. (b) Antibiotic treatment, infection and inflammation can induce IL-22mediated secretion of Lcn2 from intestinal epithelial cells, and of Lcn2 and Lf from neutrophils that are recruited to the gut. The consequent iron limitation, in turn, induces commensals and pathogens to upregulate various iron uptake mechanisms, including increasing production and secretion of siderophores. Many enteric pathogens secrete stealth siderophores that promote evasion of lipocalin-2-mediated iron sequestration, thus enabling these pathogens to outcompete the gut microbiota and thrive. 


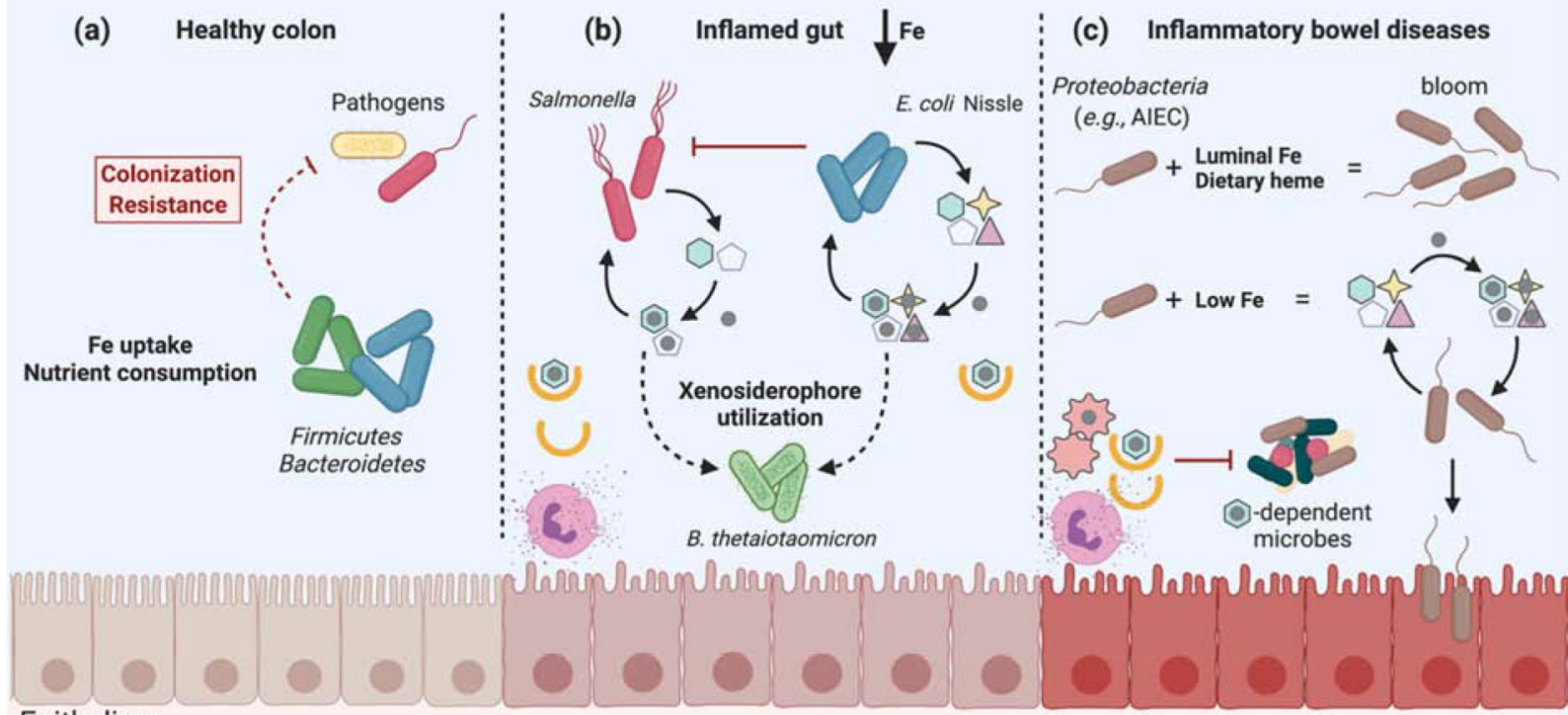

Epithelium

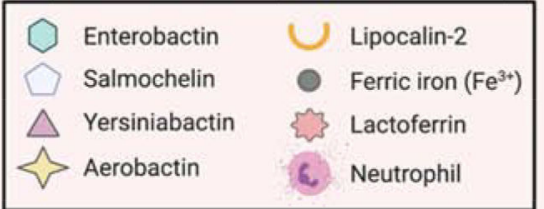

Figure 3. Iron acquisition by pathogens and commensals.

(a) In the healthy gut, the microbiota is primarily comprised of obligate anaerobes (the phyla Firmicutes and Bacteroidetes). These commensals occupy local niches, consume luminal nutrients and uptake iron $(\mathrm{Fe})$, thereby providing colonization resistance to pathogenic microbes. (b) Intestinal inflammation causes a dramatic reduction in luminal $\mathrm{Fe}$ content. The enteric pathogen Salmonella is able to scavenge $\mathrm{Fe}^{3+}$ in this environment, due to the production of salmochelin. However, secretion of multiple siderophores enables the probiotic bacterium E. coli Nissle 1917 to outcompete Salmonella. Moreover, the commensal bacterium Bacteroides thetaiotaomicron sustains colonization during inflammation by utilizing xenosiderophores, a critical mechanism to restore its original colonization state after inflammation is resolved. (c) IBD is characterized by chronic relapsing or remittent intestinal inflammation. During colitis, the increased secretion of host antimicrobial proteins lactoferrin (Lf) and lipocalin-2 (Lcn2) limits the availability of iron to gut microbes. However, the low Fe content induces the upregulation of bacterial Fe uptake genes, which contributes to the blooms of Proteobacteria frequently observed. Even high luminal Fe content (e.g., due to Fe supplementation) promotes the growth of Proteobacteria in the inflamed gut. In patients with Crohn's disease, adherent-invasive E. coli (AIEC) strains express a variety of Fe-uptake genes, which contribute to the pathogen's growth during colitis. 
(a)

\section{Siderophore} immunization
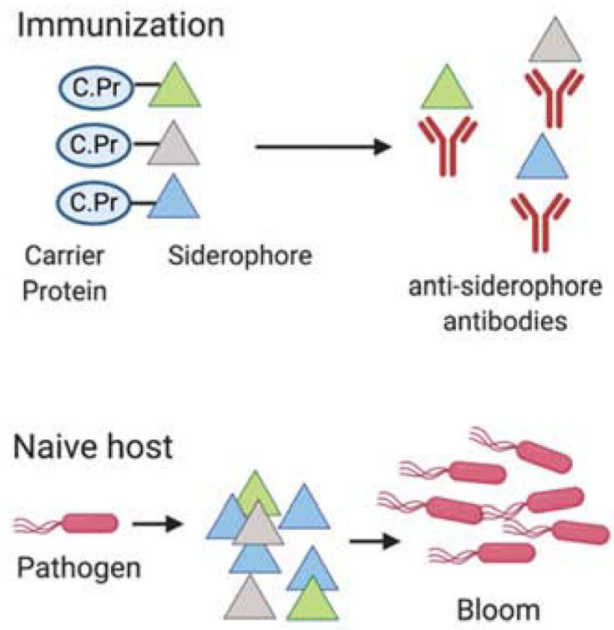

Immunized host

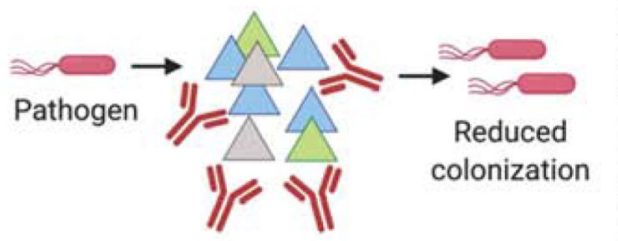

(b)

Siderophore-antibiotic conjugates

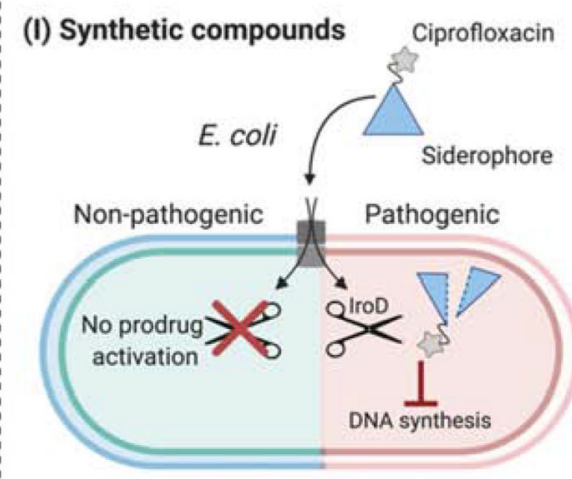

(II) Natural compounds: Microcins

Enterobacteriaceae

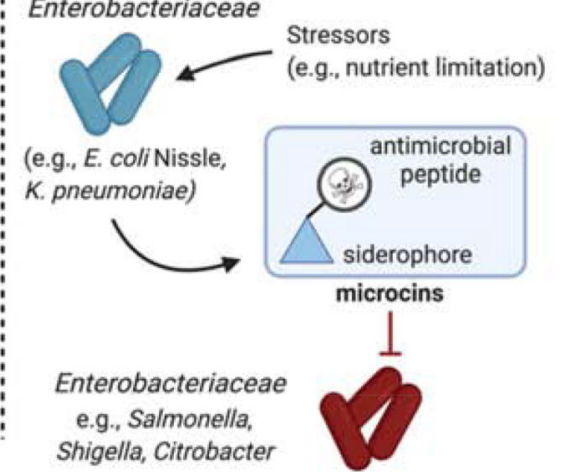

(c)

Siderophores as diagnostic tool
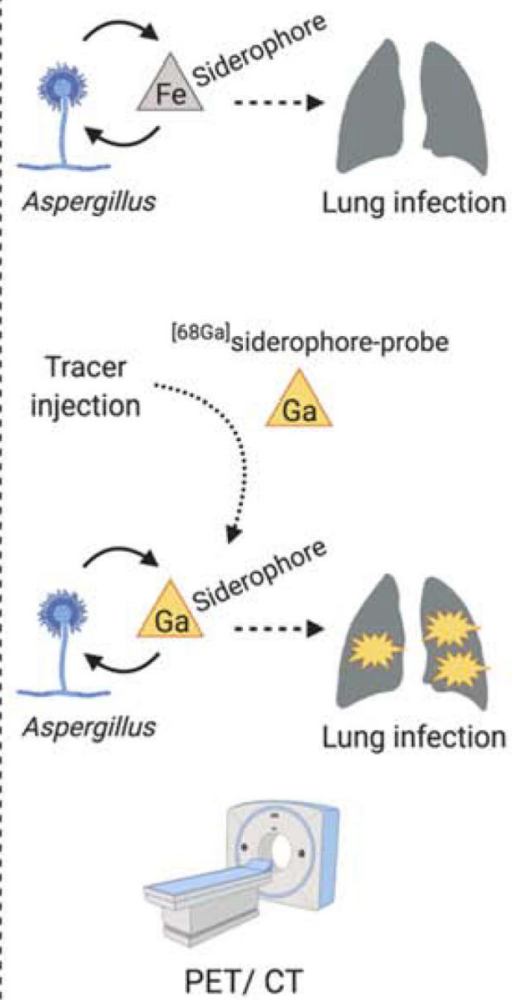

Figure 4. Siderophores as therapeutic targets and diagnostic tools.

(a) During infection, various siderophores are secreted by pathogens to thrive in the host despite host-mediated iron limitation. In experimental models, siderophores have been targeted for vaccination by linkage to a carrier protein in order to generate anti-siderophore antibodies. Whereas pathogens (e.g., Salmonella, UPEC) were able to successfully replicate in naïve hosts, siderophore-based immunization reduced their colonization levels. (b) Conjugation of antimicrobial peptides or antibiotics to siderophores. (b.I) An enterobactinciprofloxacin conjugate is transported through a common siderophore receptor found in the outer membrane of all E. coli strains. Once in the cytoplasm, the IroD esterase, which is mainly found in pathogenic $E$. coli strains, processes the enterobactin-ciprofloxacin prodrug and thereby enables ciprofloxacin-mediated inhibition of DNA synthesis. (b.II) Certain strains of Enterobacteriaceae, such as E. coli Nissle or $K$. pneumoniae, secrete microcins in response to nutrient (e.g., Fe) limitation. It is generally thought that the siderophore moiety enables these small antimicrobial peptides to better target susceptible strains of Enterobacteriaceae by utilizing their siderophore receptors for import. (c) Microbial siderophore uptake during infection can be leveraged for imaging applications. During lung infection, Aspergillus scavenges iron (Fe) via siderophores. Injection of siderophores radiolabeled with ${ }^{68} \mathrm{Ga}$ in experimental Aspergillus infections enabled the visualization of the lung infection site by PET/CT. 